\title{
Observation results of hydrophysical and hydrochemical parameters in the littoral zone of Lake Baikal
}

LIMNOLOGY FRESHWATER

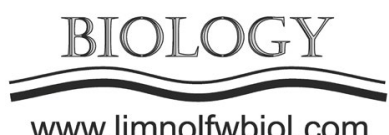

\author{
Aslamov I.A.*, Makarov M.M., Gnatovsky R.Yu., Chernyshov M.S., Kucher K.M., \\ Domysheva V.M.
}

Limnological Institute, Siberian Branch of the Russian Academy of Sciences, Ulan-Batorskaya Str., 3, Irkutsk, 664033, Russia

\begin{abstract}
The article presents the first results of field tests of the automated station developed by the researchers from Limnological Institute SB RAS for measuring hydrophysical, hydrochemical and meteorological parameters in water bodies with the real-time data transmission to a remote Internet server. We show daily and hourly variations of the main hydrophysical and hydrochemical parameters in the littoral zone and near the pier in the Bolshiye Koty settlement. A comparative analysis of the obtained data with the results of parallel chemical analyses of the daily samples revealed their good agreement.
\end{abstract}

Keywords: automated hydrometeorological station, ecological monitoring, hydrophysical processes, Lake Baikal

\section{Introduction}

Currently, shipborne observations using CTDtype instruments are the main method for studying the hydrological characteristics of Lake Baikal. They provide episodic information about the spatial distribution of temperature, mineralization and dissolved oxygen over the depth of the lake but do not provide detailed information about their temporal variability. As a rule, hydrochemical parameters are measured even more pointwise because they require sampling and subsequent analysis. To study spatiotemporal variability of ecosystem characteristics in more detail, it is necessary to combine shipborne observations with long-term measurements at coastal stations or develop a network of abyssal buoy stations equipped with various modern hydrophysical instruments.

The first step in this direction was the development and implementation of an automated hydrometeorological station (AHMS) (Makarov et al., 2018) at Limnological Institute SB RAS to organize online monitoring of hydrophysical, hydrochemical and meteorological parameters in the littoral zone of Lake Baikal.

\section{Materials and methods}

The developed station is based on an AAQ177 Rinko water quality profiler, JFE Advantech, Japan (Water quality profiler with fast optical DO sensor) and water level sensor developed at Limnological Institute SB RAS. Meteorological parameters are measured with a set of Vantage Pro 2 sensors, Davis Instruments, USA (Vantage Pro2 Specification Sheets). A complete list of hydrophysical, hydrochemical and meteorological parameters measured by the monitoring station, as well as its detailed description, are given in (Makarov, 2018). The environmental parameters measured every 10 seconds are transmitted in real time via wireless communication channels to a remote Internet server. Functionally, this server is a data collection and data processing centre (data centre). Tasks of the data centre include receiving data from the network of monitoring stations, primary processing, storage and provision of the access through the WEB page, Fig. 1 (https:// hlserver.lin.irk.ru/shs/rinko/).

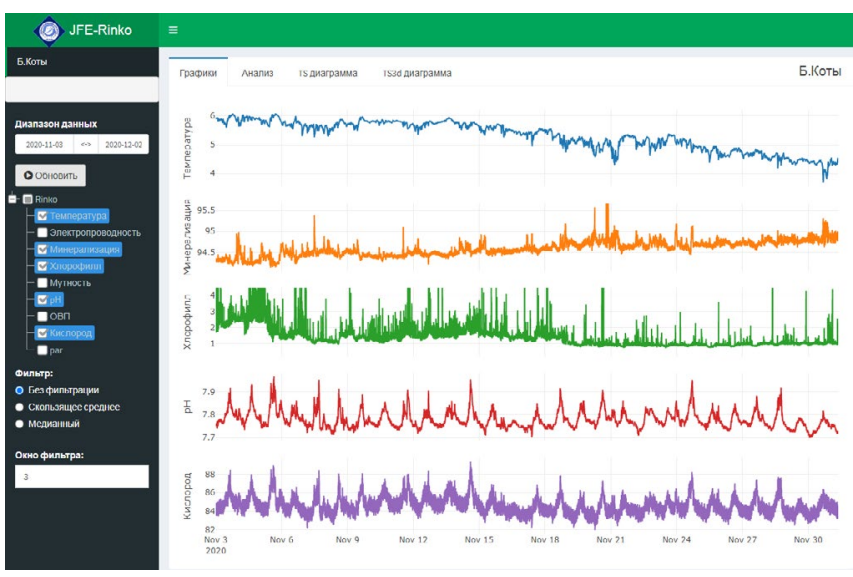

Fig.1. WEB-interface of the data centre to display data from the stations monitoring the littoral zone of Lake Baikal. 


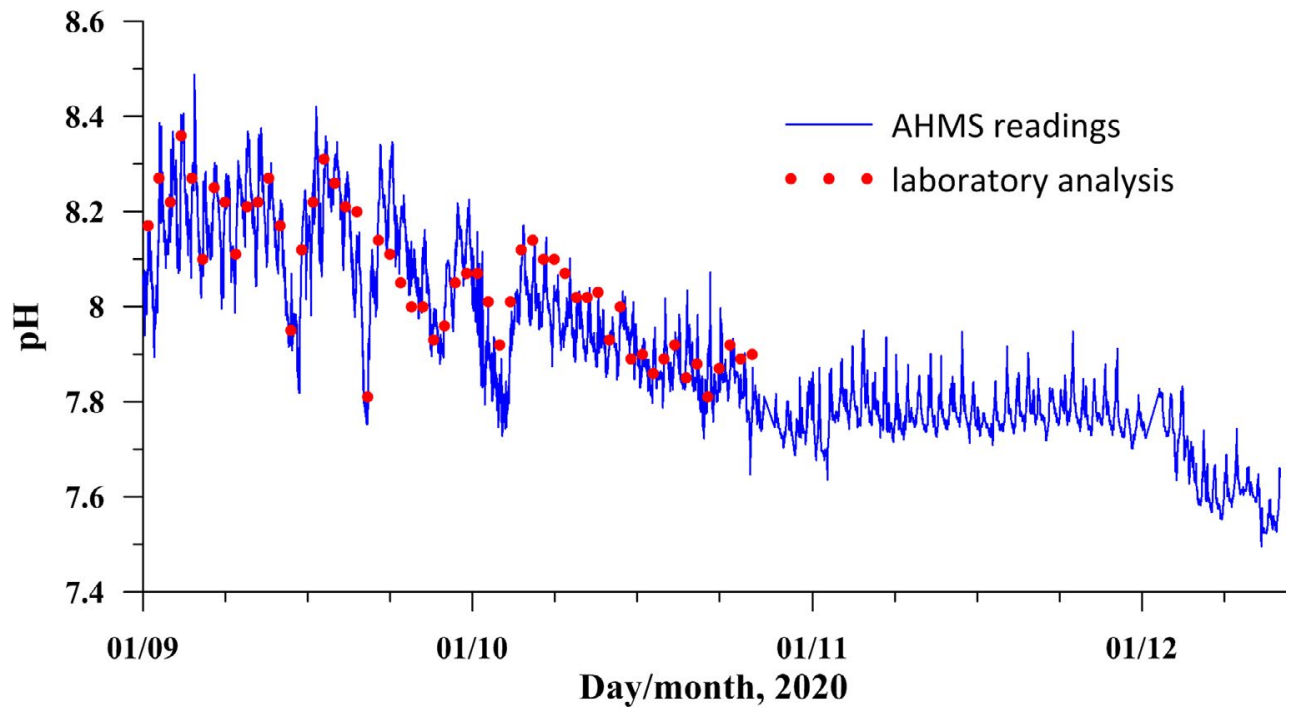

Fig.2. Comparison of the $\mathrm{pH}$ data between AHMS readings and laboratory analysis of the water near the Bolshiye Koty settlement.

It should be noted that, due to the peculiarities of the combined $\mathrm{pH}$ and ORP (oxidation-reduction potential) sensor, its operation cannot be ensured without periodic maintenance. The sensor should be systematically calibrated, and its operating life is less than two years. To facilitate maintenance, the water quality profiler was placed in a heated cabin at a pier. It was suspended $20 \mathrm{~cm}$ from the bottom of the tank, through which water was continuously pumped from a $4 \mathrm{~m}$ depth at a distance of $50 \mathrm{~m}$ from the pier.

\section{Results and discussion}

In August 2020, the monitoring station was installed at the pier of Limnological Institute SB RAS in the Bolshiye Koty settlement. Data analysis revealed diurnal variations of $\mathrm{pH}$ and dissolved oxygen (Fig. 1). It is impossible to obtain such high-frequency series by conventional methods using sampling and laboratory instruments. Fig. 2 shows comparison of the $\mathrm{pH}$ data obtained by the automated station with the results of parallel chemical analyses of samples. There is a visually good agreement between the results.

The essential parameters affecting the state of the littoral zone of Lake Baikal are water temperature and its mineralization. During the autumn cooling of the lake, the surface waters are cooled with their subsequent mixing to the depth of the temperature of maximum density (autumn homothermy). At the same time, mineralization gradually increases owing to water evaporation and alongshore ice formation (Fig. 3).

Fig. 4 shows a comparison of the data on chlorophyll $a$ obtained from AHMS with the measurements of the nutrient concentrations (nitrogen and phosphorus oxides), which were carried out daily at the pier in the Bolshiye Koty settlement. Obviously, there is the feedback: with a decrease in chlorophyll, the concentrations in nitrates and phosphates increase, and with its high values, the concentrations of nutrients remain low, which may indicate the consumption of nutrients by phytoplankton.

In general, it is noteworthy that the set of measured parameters of AHMS is sufficient to assess water quality and track its changes over time.

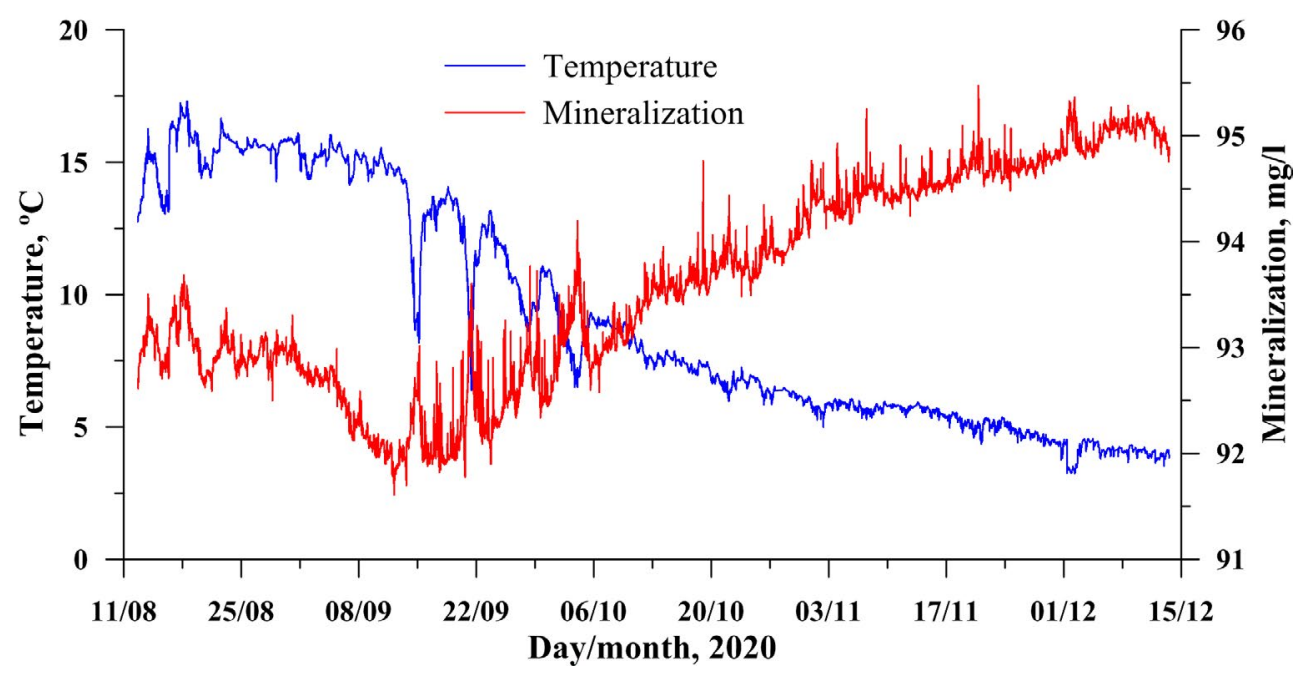

Fig. 3. Changes in temperature and mineralization of the water near the Bolshiye Koty settlement. 


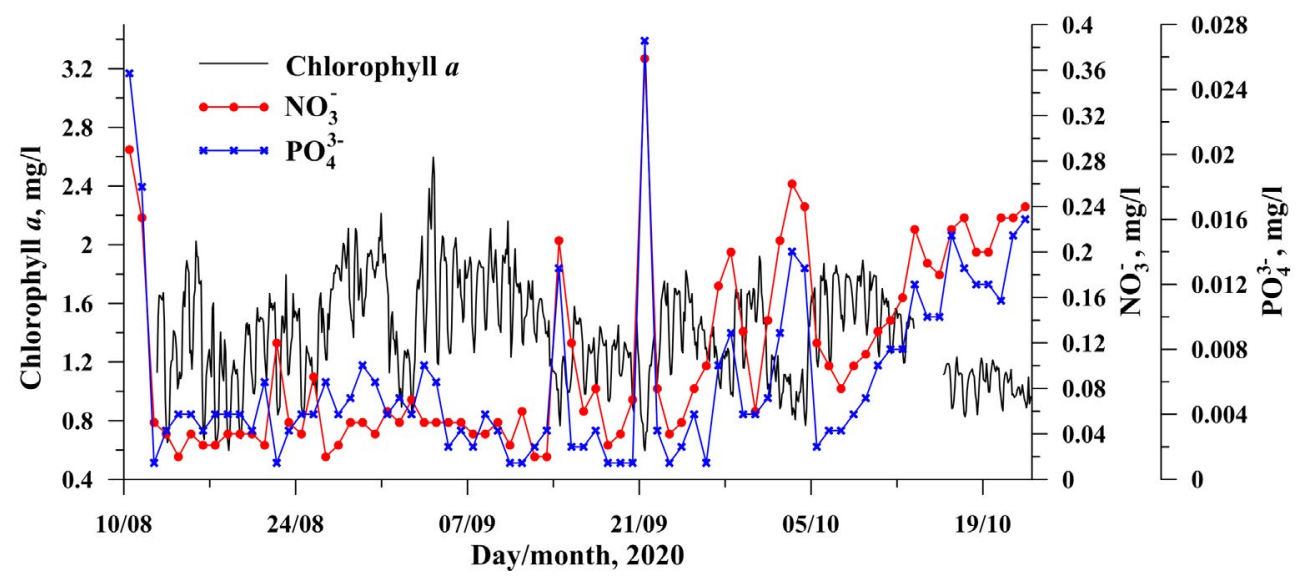

Fig.4. Comparison of the data on chlorophyll $a$ obtained with AHMS and laboratory measurements of the concentrations of nitrates and phosphates.

\section{Conclusions}

We developed an autonomous complex for measuring hydrophysical, hydrochemical and hydrooptical parameters in the littoral zone of Lake Baikal, which was installed near the Bolshiye Koty settlement. Data access is provided via the Internet in real time. The obtained comparatively high-frequency and quasi-continuous measurements of the indicated parameters allowed us for the first time to trace in detail their daily and monthly variations during the summer-winter transition period. Comparison of the data obtained by the automated station with the results of the parallel chemical analyses of samples for $\mathrm{pH}$ indicated their good agreement. The development of systems for online monitoring of water balance parameters, such as water temperature, solar irradiance, wind regime, chemical and biogenic elements, etc., can provide additional information to understand the causes of the recent ecological transformation of the littoral zone of Lake Baikal. Thus, we will be able to switch from discrete/one-time observations to quasicontinuous ones, which will significantly improve the forecasting of natural and anthropogenic phenomena that are hazardous for the residents and ecosystem of the Baikal natural territory, and will form the basis for the development of the solutions for their prevention or mitigation.

\section{Acknowledgements}

The work was supported by the grant No. 07515-2020-787 in the form of a subsidy for a Major scientific project from Ministry of Science and Higher Education of Russia (project "Fundamentals, methods and technologies for digital monitoring and forecasting of the environmental situation on the Baikal natural territory") and Russian Academy of Science, project No. 0341-2019-0004 ("Fundamental research and breakthrough technologies as a basis for advanced development of the Baikal region and its inter-regional relations").

\section{References}

Makarov M.M., Kucher K.M., Aslamov I.A. et al. 2018. The monitoring system of hydrophysical and hydrochemical parameters of Lake Baikal. Mezhdunarodnyy Zhurnal Prikladnykh i Fundamental'nykh Issledovaniy [Journal of Applied and Fundamental Sciences] 12(1): 120-124. DOI: 10.17513/mjpfi.12533 (in Russian)

\begin{tabular}{|c|c|}
\hline ge & Pro2 \\
\hline avis & Instruments. \\
\hline
\end{tabular}

davisinstruments.com/product_documents/weather/ spec_sheets/6152_62_53_63_SS.pdf

Water quality profiler with fast optical DO sensor // JFE Advantech. URL: https://www.jfe-advantech.co.jp/eng/ ocean/pdf/AAQ-RINKO(E)_201607.pdf 